\title{
The direct power control of three-phase AC-DC converter under unbalance voltage condition
}

\author{
Nor Azizah Yusoff, Azziddin M. Razali, Kasrul Abdul Karim, Auzani Jidin \\ Faculti Kejuruteraan Elektrik, Universiti Teknikal Malaysia Melaka (UTeM), Malaysia
}

\begin{abstract}
Article Info
Article history:

Received Apr 9, 2019

Revised Jul 1, 2019

Accepted Jul 9, 2019

\section{Keywords:}

Direct power control

Negative sequence

Positive sequence

Total harmonic distortion

Unbalance condition

ABSTRACT

This paper presents the integrated approach for three-phase PWM AC-DC converter for obtaining the symmetrical components under unbalanced supply condition. In the cases of unbalanced three-phase system, it causes the presence of unbalanced current and voltages thus produce the negative components on the grid voltage. Otherwise, the unbalance voltage in a threephase power system causes severe performance degradation of a grid connected VSI. Therefore, the input structures for conventional direct power control have been modified with a three simpler sequence networks instead it coupled by a detailed three-phase system method. Thus, the imbalance voltage can be resolved by separating from the individual elements of voltage and current into symmetrical components called as a sequence network. Consequently, the input power is relatively improved during unbalanced condition almost than $70 \%$. It proven through the measurement of Total Harmonic Distortion (THD) from the conventional direct power control in individual elements is much higher compared than it resolved in separate components. Therefore, three symmetrical components are necessary for imbalance supply condition in order to obtaining the good quality of sinusoidal grid currents.
\end{abstract}

Copyright @ 2019 Institute of Advanced Engineering and Science. All rights reserved.

\section{Corresponding Author:}

Azziddin Bin Mohamad Razali,

Faculty of Electrical Engineering,

Universiti Teknikal Malaysia Melaka (UTeM),

76100 Durian Tunggal, Malacca, Malaysia.

Email: azziddin@utem.edu.my

\section{INTRODUCTION}

Nowadays, almost every application in electric system that needs the power converter is necessary especially in dc motor control circuits and much more [1]. Power converter acts as the link or the transforming stage between the power source and the power supply output. However, based on [2] stated that a converter is relevant to one or more functions by delivering output differs which is from the input. It is used to increase or decrease the magnitude of input voltage, invert polarity, or to produce several output voltages of either the same polarity with the input, different polarity, or mixed polarities such in the computer power supply unit. Performance of power converters is greatly dependent on the quality of the control techniques that being applied to the converters. Therefore, the operating conditions affected by a variety of unbalance grid voltage supply or other kind of disturbance at grid side. The most usual grid faults are under amplitude variation which is the three-phase voltage differ in amplitude or are displaced from their normal $120^{\circ}$ phase relationship or both. Indirectly, it implies for the appearance of negative sequence in voltage and current thus leads to the oscillation of system variable. Thus, to achieve a lower disturbances and enhanced power quality, a few solutions have been approach in these cases. Therefore, the solution should be based in controlling the positive sequence power to obtain symmetrical ac currents. There has also been direct power control (DPC) approaches in order to improve the whole performance in controller [3-5]. In this paper, DPC is modified to manage power flow during unbalanced voltage supply so that sinusoidal balanced grid 
currents are obtained. With this new strategy, DPC overcomes the problems related to grid voltage imbalance and can accomplish new regulation laws.

\section{DIRECT POWER CONTROL}

The direct power control (DPC) is based on the direct torque control concept in electrical machines. The intention for DPC is to control the instantaneous of active and reactive power control loops [6] as the same direction for DTC in controlling the torque and flux of induction machines. In this DPC scheme as shown in Figure 1, switching table plays a major part [7]. The input to the switching table will be the instantaneous error of the active power, reactive power and the voltage vector position. This switching table enables the converter to select the appropriate of switching states. In conventional DPC, a total of four voltage sensors are used to measure the three-phase ac input voltage and dc output voltage, while three current sensors are used to measure the three-phase input currents [8-10]. Then, the measured currents and voltages are fed into two " $a b c-\alpha \beta$ " blocks which utilize the Clarke Transformation. Both blocks transform the three-phase voltage and current into their corresponding $\alpha \beta$-reference frame. The transformation matrix to the stationary frame is utilized by referring the (1). The three-phase input components are represented by $x_{a}, x_{b}$ and $x_{c}$ while $x_{\alpha}$ and $x_{\beta}$ indicate two-phase components in $\alpha \beta$-reference frame. The voltage and current in $\alpha \beta$-reference frame are then fed into another block to obtain the estimated instantaneous active power $P_{\text {inst }}$, and reactive power $Q_{i n s t}$, as indicated in (2) and (3), respectively. Then, the $P_{\text {inst }}$ and $Q_{\text {inst }}$ are fed into the hysteresis comparator to obtain active and reactive power errors which is given by $d_{P}$ and $d_{Q}$ respectively. Subsequently, the angle of input voltage vector $\theta_{n}$, is determined by the voltage vector angle converter block. The inputs to the switching table are $\theta_{n}, d_{P}$ and $d_{Q}$. At that point, the suitable switching states of the converter will be generated by the switching table and the output voltage is kept close to the reference DC voltage by tuning the $P I$ controller appropriately $[11,12]$.

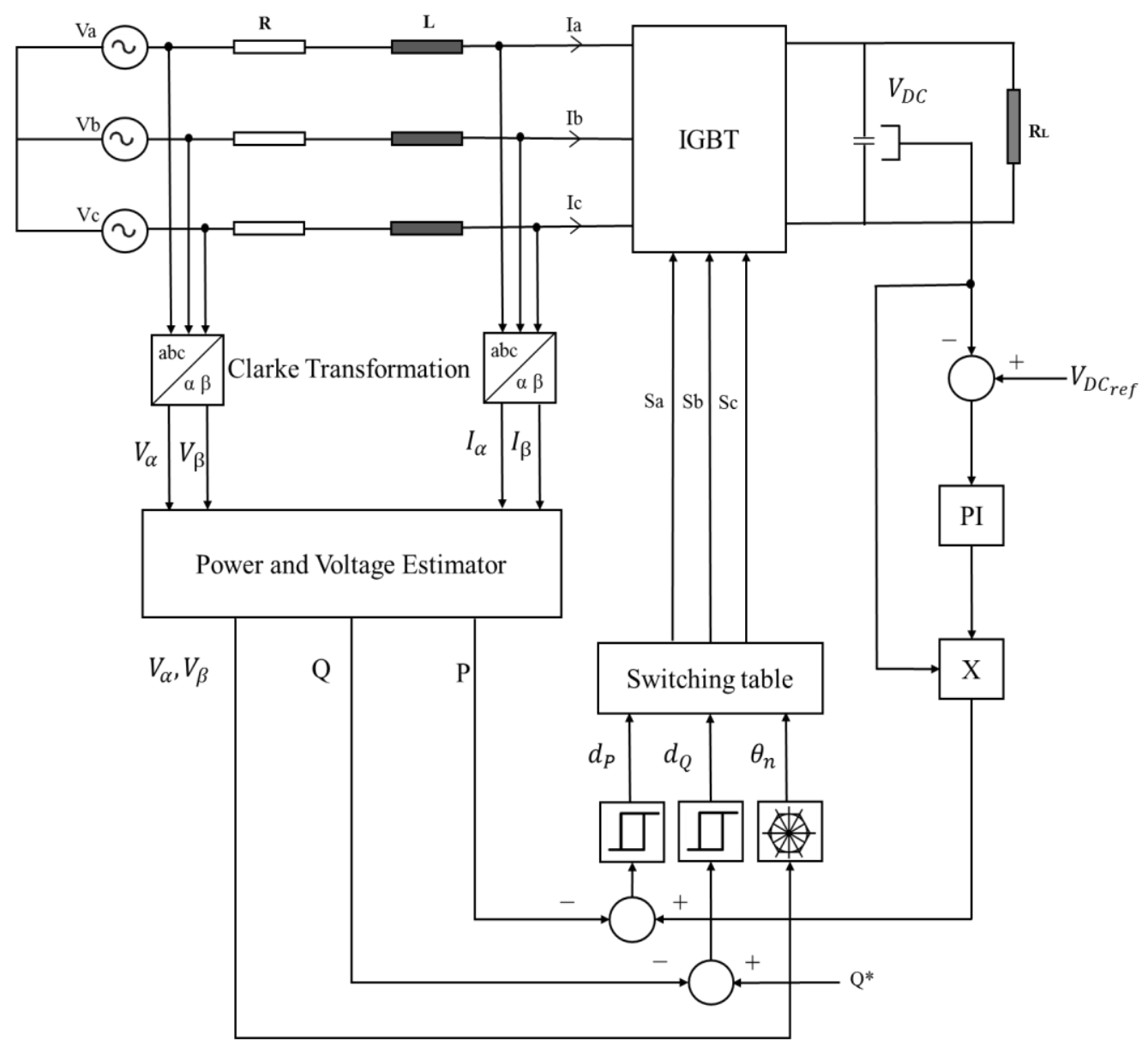

Figure 1. Control structure of direct power control 


$$
\begin{aligned}
& {\left[\begin{array}{l}
x_{\alpha} \\
x_{\beta}
\end{array}\right]=\frac{2}{3}\left[\begin{array}{ccc}
1 & -\frac{1}{2} & -\frac{1}{2} \\
0 & \frac{\sqrt{3}}{2} & -\frac{\sqrt{3}}{2}
\end{array}\right]} \\
& P_{\text {inst }}=\frac{3}{2}\left[V_{\alpha} I_{\alpha}+V_{\beta} I_{\beta}\right] \\
& Q_{\text {inst }}=\frac{3}{2}\left[V_{\beta} I_{\alpha}-V_{\alpha} I_{\beta}\right]
\end{aligned}
$$

\section{Development of switching table for DPC}

In DPC, the digitized signal $\theta_{n}$ is calculated from the phase of voltage vector, which is measured from the three-phase power source using

$$
\theta=\tan ^{-1}\left(\frac{V_{\beta}}{V_{\alpha}}\right)
$$

The switching table in the circuit simulation is created using "Matlab Function" block as shown in Table 1. The power errors are inputs to the hysteresis comparators and digitized to $d_{P}$ and $d_{Q}$. Figure 2 shows the sector selection for direct power control.

Table 1. Switching look-up table for direct power control

\begin{tabular}{cccccccccccccc}
\hline \begin{tabular}{c} 
Power error \\
\multicolumn{1}{c}{ status }
\end{tabular} & \multicolumn{10}{c}{ Sector position $\left(\theta_{\mathrm{n}}\right)$ and converter voltage vector $\left(\mathrm{V}_{\mathrm{n}}\right)$} \\
\hline$d_{P}$ & $d_{Q}$ & $\theta_{1}$ & $\theta_{2}$ & $\theta_{3}$ & $\theta_{4}$ & $\theta_{5}$ & $\theta_{6}$ & $\theta_{7}$ & $\theta_{8}$ & $\theta_{9}$ & $\theta_{10}$ & $\theta_{11}$ & $\theta_{12}$ \\
0 & 0 & $\mathrm{~V}_{1}$ & $\mathrm{~V}_{1}$ & $\mathrm{~V}_{2}$ & $\mathrm{~V}_{2}$ & $\mathrm{~V}_{3}$ & $\mathrm{~V}_{3}$ & $\mathrm{~V}_{4}$ & $\mathrm{~V}_{4}$ & $\mathrm{~V}_{5}$ & $\mathrm{~V}_{5}$ & $\mathrm{~V}_{6}$ & $\mathrm{~V}_{6}$ \\
0 & 1 & $\mathrm{~V}_{2}$ & $\mathrm{~V}_{2}$ & $\mathrm{~V}_{3}$ & $\mathrm{~V}_{3}$ & $\mathrm{~V}_{4}$ & $\mathrm{~V}_{4}$ & $\mathrm{~V}_{5}$ & $\mathrm{~V}_{5}$ & $\mathrm{~V}_{6}$ & $\mathrm{~V}_{6}$ & $\mathrm{~V}_{1}$ & $\mathrm{~V}_{1}$ \\
1 & 0 & $\mathrm{~V}_{6}$ & $\mathrm{~V}_{6}$ & $\mathrm{~V}_{1}$ & $\mathrm{~V}_{1}$ & $\mathrm{~V}_{2}$ & $\mathrm{~V}_{2}$ & $\mathrm{~V}_{3}$ & $\mathrm{~V}_{3}$ & $\mathrm{~V}_{4}$ & $\mathrm{~V}_{4}$ & $\mathrm{~V}_{5}$ & $\mathrm{~V}_{5}$ \\
1 & 1 & $\mathrm{~V}_{3}$ & $\mathrm{~V}_{3}$ & $\mathrm{~V}_{4}$ & $\mathrm{~V}_{4}$ & $\mathrm{~V}_{5}$ & $\mathrm{~V}_{5}$ & $\mathrm{~V}_{6}$ & $\mathrm{~V}_{6}$ & $\mathrm{~V}_{1}$ & $\mathrm{~V}_{1}$ & $\mathrm{~V}_{2}$ & $\mathrm{~V}_{2}$ \\
\hline
\end{tabular}

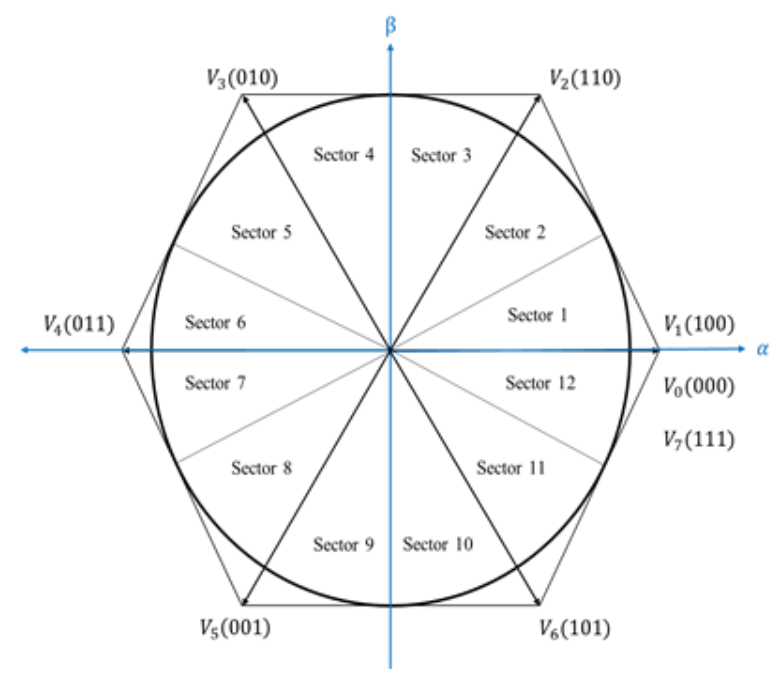

Figure 2. Sector selection for direct power control

\section{UNBALANCE GRID VOLTAGE}

However, although DPC offer simple control structure and fast dynamic response, it generates high ripples and higher number of Total Harmonic Distortion (THD) during imbalance input voltage. In order to make the controller to be more robust in such cases, investigations of power converters under unbalanced input voltage conditions are presented in references [13]. The interaction between the harmonic components of the dc output voltage and the converter pole voltages creates odd harmonic components in the input AC

The direct power control of three-phase AC-DC converter under unbalance voltage ... (Nor Azizah Yusoff) 
current. Consequently, these harmonics components will increase the THD of the ac input current significantly [14]. In general, the nonideal conditions such as unbalanced and distorted three-phase grid voltage supply have negative impacts to the performance and filter size of AC-DC converter system [15]. Therefore, the control techniques of an AC-DC converter need additional investigation to mitigate those negative impacts during voltage unbalance and distorted conditions. For that, it is necessary to split the voltage vector into its sequence components as well as to compute the positive sequence voltage vector angle. Voltage angle calculation is done by means of a $P L L$ while a very simple algorithm is used for sequence extraction.

\subsection{Sequence extractor}

The unbalanced grid voltage condition in DPC causing negative or zero components exist on the grid voltage vector. Thus, it indicates to harmful to all polyphase loads, especially three phase induction machines. Otherwise, unbalance system is produce excessive heat causing to equipment failures. Therefore, positive and negative sequence equations is shown in Table 2 will be applied in this research work in order to obtain a balanced and low total harmonic distortion of grid currents.

Table 2. Sequence extractor equation

\begin{tabular}{cc}
\hline Phase Component & Matrix Equation \\
\hline Zero Sequence & {$\left[\begin{array}{l}V_{a}^{(0)} \\
V_{b}^{(0)} \\
V_{c}^{(0)}\end{array}\right]=\frac{1}{3}\left[\begin{array}{lll}1 & 1 & 1 \\
1 & 1 & 1 \\
1 & 1 & 1\end{array}\right]\left[\begin{array}{l}V_{a} \\
V_{b} \\
V_{c}\end{array}\right]$} \\
Positive Sequence & {$\left[\begin{array}{l}V_{a}^{(1)} \\
V_{b}^{(1)} \\
V_{c}^{(1)}\end{array}\right]=\frac{1}{3}\left[\begin{array}{ccc}1 & a & a^{2} \\
a^{2} & 1 & a \\
a & a^{2} & 1\end{array}\right]\left[\begin{array}{l}V_{a} \\
V_{b} \\
V_{c}\end{array}\right]$} \\
Negative & {$\left[\begin{array}{l}V_{a}^{(2)} \\
V_{b}^{(2)} \\
V_{c}^{(2)}\end{array}\right]=\frac{1}{3}\left[\begin{array}{ccc}1 & a^{2} & a \\
a & 1 & a^{2} \\
a^{2} & a & 1\end{array}\right]\left[\begin{array}{l}V_{a} \\
V_{b} \\
V_{c}\end{array}\right]$}
\end{tabular}

Where,

$$
a=e^{j 120^{\circ}}=-\frac{1}{2}+j \frac{\sqrt{3}}{2}
$$

and

$$
a^{2}=e^{j 240^{0}}=-\frac{1}{2}-j \frac{\sqrt{3}}{2}
$$

Then, in Figure 3 has shown the block diagram for sequence extractor for from three-phase input supplies. From the figure the input voltage and current has been extracted into three-phase component, which is zero, positive and negative sequences. Next, the phase of input voltage and current from phase sequence are being transformed into alpha-beta and finally to $d q$-reference frame. Lastly, the $d q$-reference frame from only positive and negative sequence is then fed into another block in order to obtain the estimated instantaneous active power $P$, and reactive power $Q$. At the time of unbalanced condition, there is only positive and negative phasor component exist while the zero sequence component is in phase.

The instantaneous of the input power $P$ and reactive power $Q$ in a stationary reference frama is given by (7) and (8), respectively.

$$
\begin{aligned}
& p_{\text {out }}(t)=\frac{3}{2}\left(v_{\alpha}^{+} i_{\alpha}^{+}+v_{\beta}^{+} i_{\beta}^{+}+v_{\alpha}^{-} i_{\alpha}^{-}+v_{\beta}^{-} i_{\beta}^{-}+v_{\alpha}^{+} i_{\alpha}^{-}+v_{\beta}^{+} i_{\beta}^{-}+v_{\alpha}^{-} i_{\alpha}^{+}+v_{\beta}^{-} i_{\beta}^{+}+v_{\alpha}^{+} i_{\beta}^{-}-v_{\beta}^{+} i_{\alpha}^{-}+v_{\beta}^{-} i_{\alpha}^{+}-v_{\alpha}^{-} i_{\beta}^{+}\right) \\
& Q_{\text {out }}(t)=\frac{3}{2}\left(v_{\beta}^{+} i_{\alpha}^{+}-v_{\beta}^{+} i_{\beta}^{+}-v_{\beta}^{-} i_{\alpha}^{-}+v_{\alpha}^{-} i_{\beta}^{-}-v_{\alpha}^{+} i_{\beta}^{-}+v_{\beta}^{+} i_{\alpha}^{-}-v_{\beta}^{-} i_{\alpha}^{+}+v_{\alpha}^{-} i_{\beta}^{+}+v_{\alpha}^{+} i_{\alpha}^{-}+v_{\beta}^{+} i_{\beta}^{-}+v_{\alpha}^{-} i_{\alpha}^{+}+v_{\beta}^{-} i_{\beta}^{+}\right)
\end{aligned}
$$




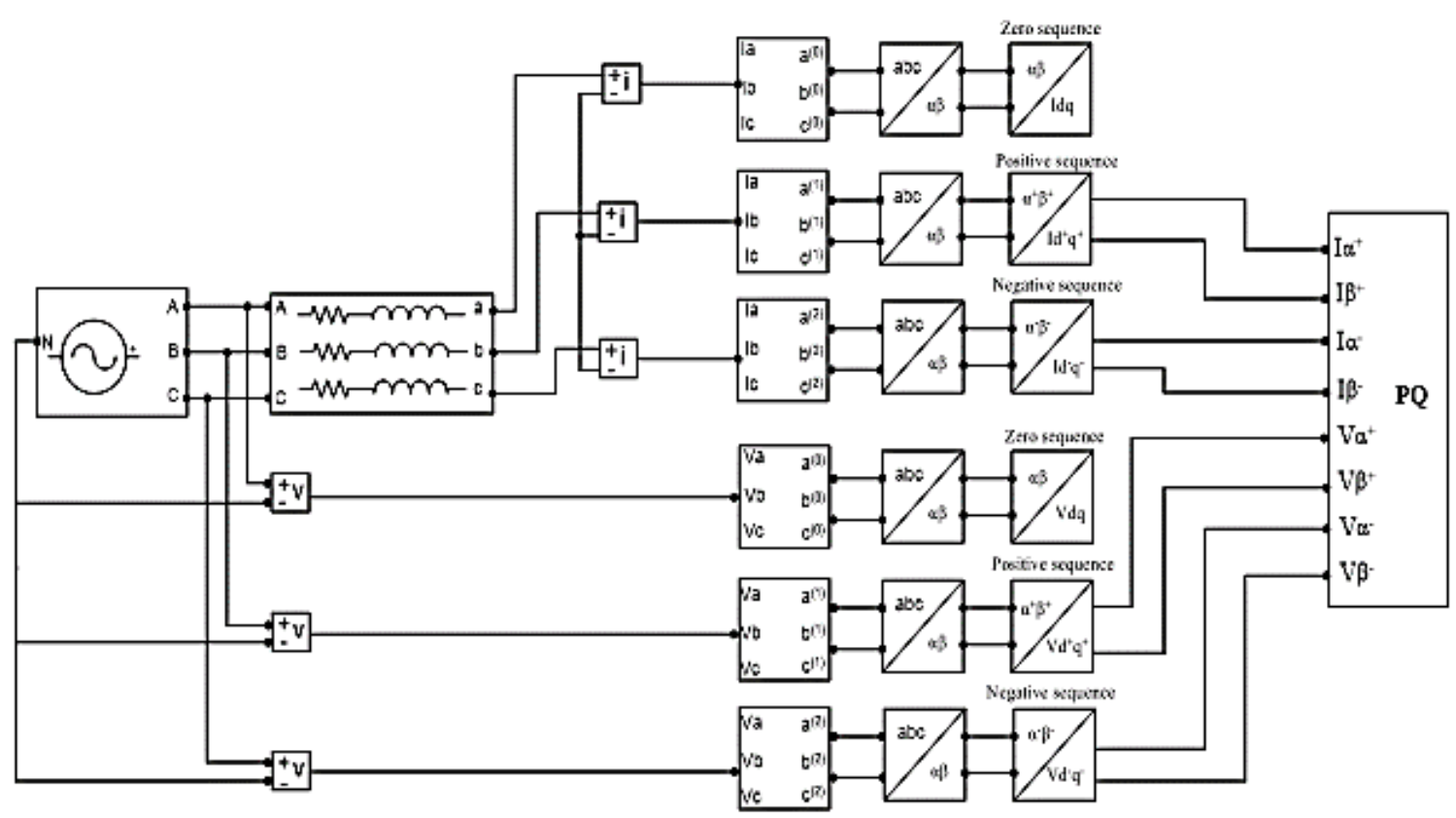

Figure 3. Block diagram for sequence extractor

\section{RESULT AND DISCUSSION}

Voltage unbalance is often occurring in supply system. Therefore, the unbalance voltage can be defining as a voltage variation in a power system in which the voltage magnitudes or the phase differences between them are not equal. Hence, in order to confirm the effectiveness of the additional strategy of sequence extractor into DPC control system, a model of the proposed control strategy for DPC during voltage unbalance has been simulated using MATLAB/Simulink. The simulation has been carried out using the main electrical parameter data used in the study is tabulated in Table 3. Several tests were conducted to verify the feasibility and performance of new DPC combining with sequence extractor compared to the conventional one during unbalanced conditions.

Table 3. Main parameter used insimulation

\begin{tabular}{lc}
\hline \multicolumn{1}{c}{ Parameters } & Value \\
\hline Input phase voltage (peak), $\mathrm{E}_{\mathrm{g}}$ & $70.71 \mathrm{~V}$ \\
Source Voltage frequency, $\mathrm{f}$ & $50 \mathrm{~Hz}$ \\
Dc-link volatage reference, $\mathrm{V}_{\mathrm{dc}, \text { ref }}$ & $200 \mathrm{~V}$ \\
Resistance of reactance, $\mathrm{R}$ & $0.2 \Omega$ \\
Inductance of reactance, $\mathrm{L}$ & $18 \mathrm{mH}$ \\
Dc-link capacitor, C & $10.8 \mathrm{mF}$ \\
Load Resistance, $\mathrm{R}_{\mathrm{L}}$ & $140 \Omega$ \\
Sampling time, $\mathrm{t}_{\mathrm{s}}$ & $20 \mu \mathrm{s}$ \\
\hline
\end{tabular}

Simulation result of the three-phase PWM rectifier operation under unbalanced input voltage for the additional of sequence extractor into DPC and conventional one are presented in Figure 4 and Figure 5 respectively. In this test, the magnitude for $V_{a}$ is differ from the nominal balanced conditioned as shown in (a) for both test. Thus, by reducing amount of voltage resulting the current to an excessive amount as shown in Figure 4 and Figure 5(b), which the current for $I_{a}$ is higher than other phases. Therefore, the additional of sequence extractor into DPC has guarantee for almost or near sinusoidal input current waveform as shown in Figure 4(c) by correcting the unbalance of input voltage. Consequenly, it resulting for a lower number of Total Harmonic Distortion (THD=6.48\%). However, input current for conventional DPC are highly distorted due to higher number of Total Harmonic Distortion (THD $=22.27 \%$ ) as shown in current spectrum. 


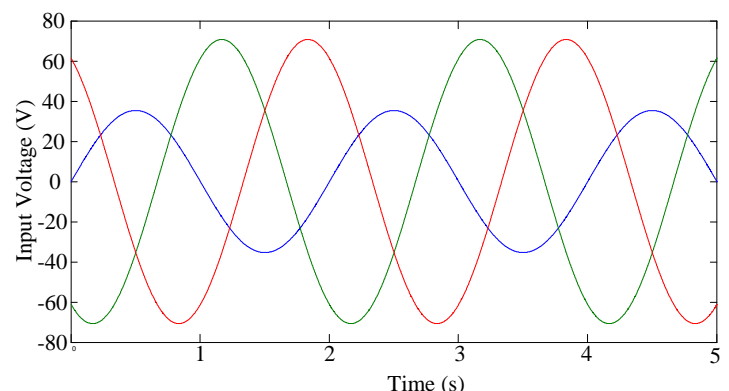

(a)

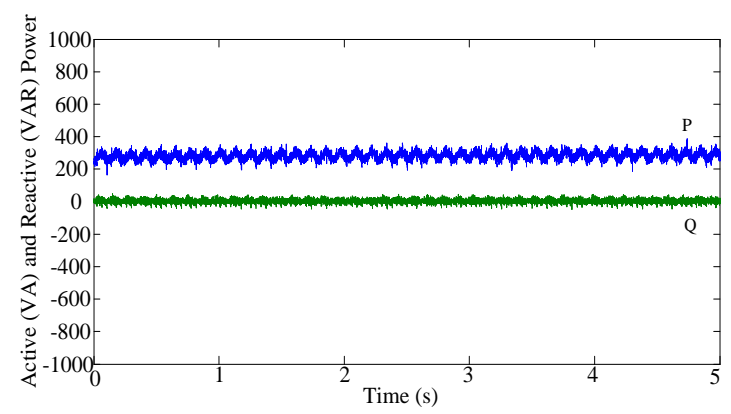

(c)

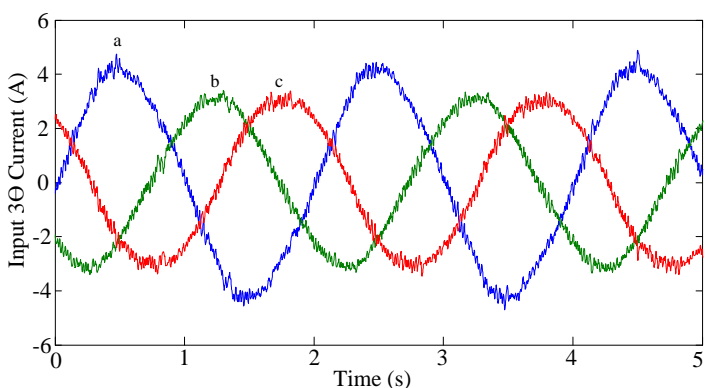

(b)

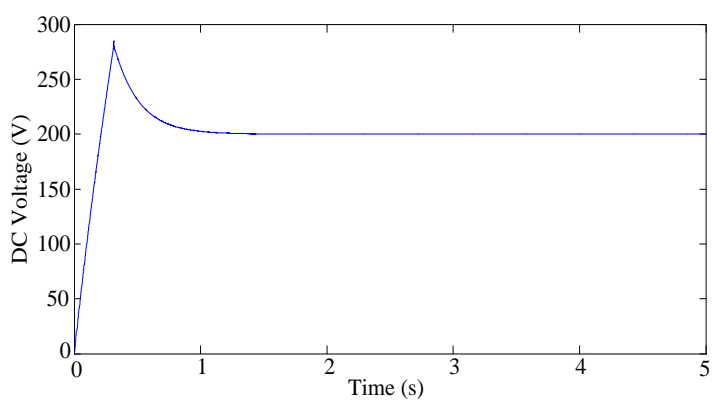

(d)
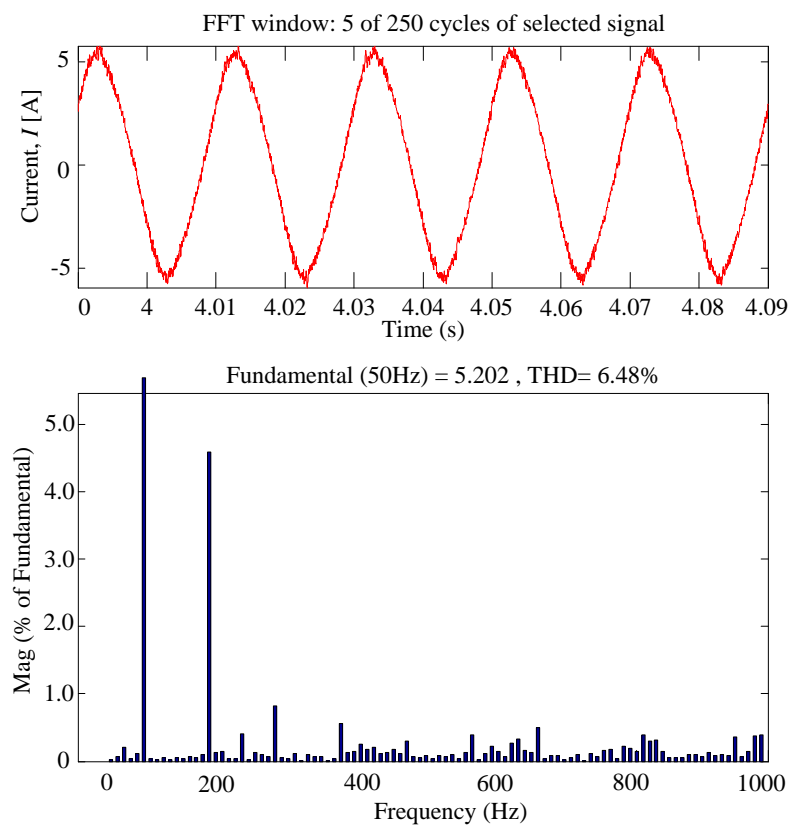

(e)

Figure 4. Simulation result for additional of sequence extractor into DPC of PWM AC-DC converter under unbalanced input voltage 


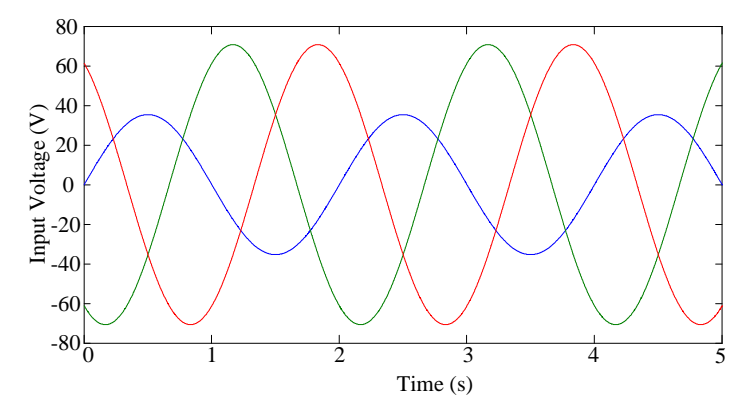

(a)

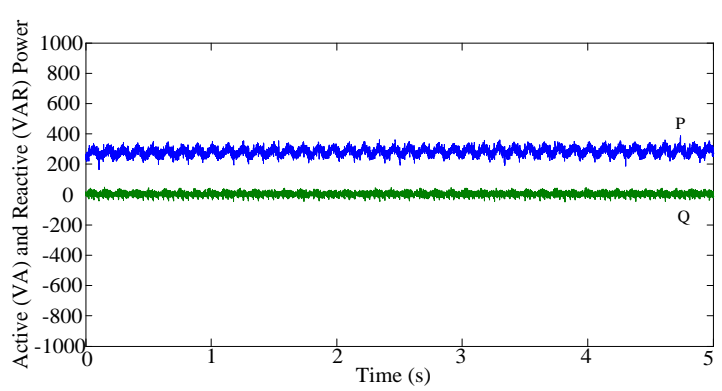

(c)

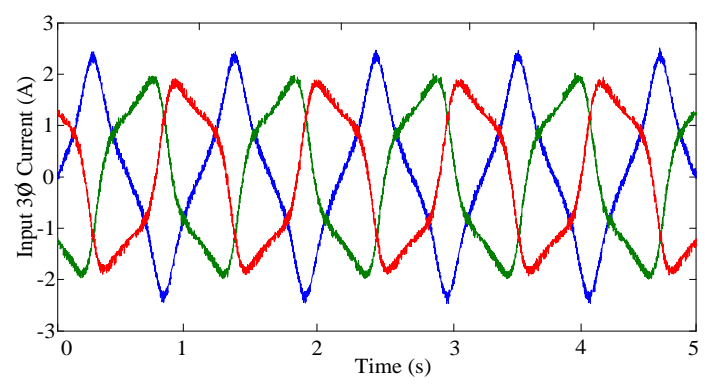

(b)

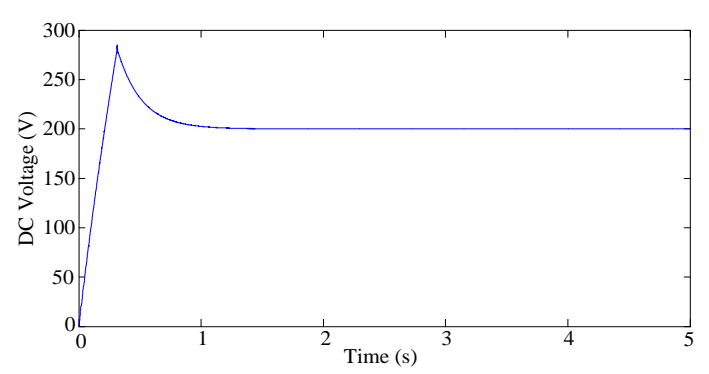

(d)
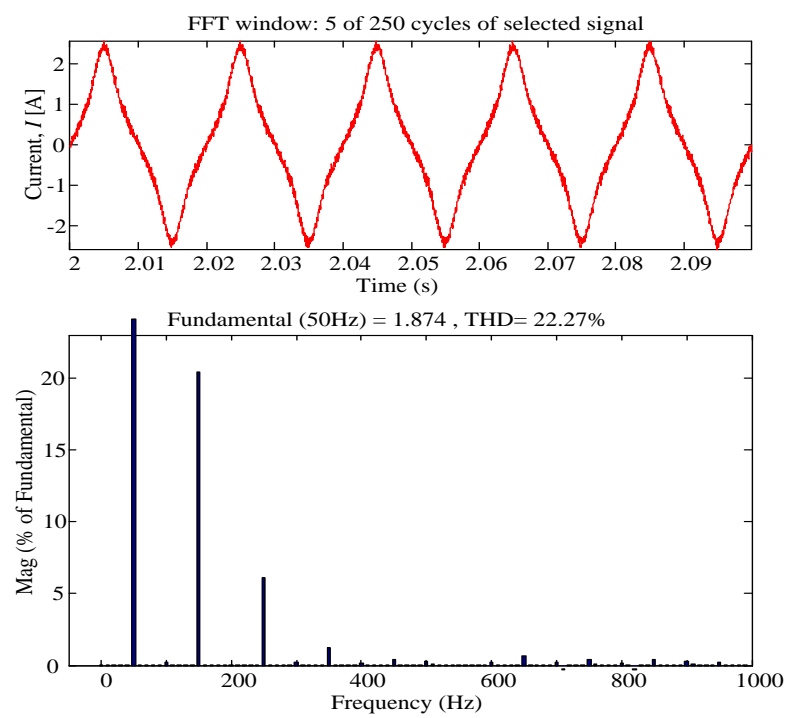

(e)

Figure 5. Simulation result for conventional DPC of PWM AC-DC converter under unbalanced input voltage

\section{CONCLUSION}

This paper has presented the implementation of a sequence extractor into Direct Power Control scheme. The main goal for the additional strategy of sequence extraxtor is to achieve for near-sinusoidal input current waveform of the converter under different amplitude input voltage conditions. In-fact, instantaneous active and reactive powers provided by harmonic component of input current are directly controlled via a switching table. Simulation result has proven excellent performance of the proposed additional strategy of sequence extractor, which is much better than conventional DPC by reducing almost for $70 \%$ of Total Harmonic Distortion (THD), even in both transient and steady states conditions. Nearly sinusoidal waveform of input current is successfully achieved under unbalance input voltage conditions. The presented simulation results confirm that the additional of sequence extractor into DPC is capable to ensure the correcting unbalance of input voltage, unlike the conventional DPC is resulting for decreasing percentage of productive current, thus it providing for high number of THD current. 


\section{ACKNOWLEDGMENT}

The authors would like to thank toward 'Skim Zamalah' from Universiti Teknikal Malaysia Melaka (UTeM)' as providing for continuous financial support that enabled the achievement of this research result and Ministry of Education (KPM) for sponsoring this research work under grant (FRGS/1/2016/TK04/UTEM/02/11/F00307)

\section{REFERENCES}

[1] K. Venkateshvarlu and Ch. Chengaiah, "Comparative study on DC motor speed control using various controllers," Global Journal of Researchers in Engineering Electrical and Electronics Engineering, vol. 13(17), 2013.

[2] Wang Feng and Luo Yutao, "Modelling of a power converter with multiple operating modes," World Electric Vehicle Journal, pp. 1-17, 2018.

[3] Dawei Zhi, Lie Xu, and Barry W. Williams, "Improved direct power control of grid-connected DC/AC converter," IEEE Transaction Power Electronic, vol. 24(5), 2009.

[4] Zhang, Y., Li, Z., Zhang, Y., Xie, W., Piao, Z., and Hu, C., "Performance improvement of direct power control of PWM rectifier with simple calculation," IEEE Transactions on Power Electronics, vol. 28(7), pp. 3428-3437, 2013.

[5] Jingjing Huang, Fanghong Guo, Changyun Wen, Bo Yang and Jianfang Xiao, "A direct power control strategy on best switching state approach," IEEE Transaction Power Electronic, vol. 6(4), 2018.

[6] D. Sun, X. Wang, and Y. Fang, "Backstepping direct power control without phase-locked loop of AC/DC converter under both balanced and unbalanced grid conditions," IET Power Electron., vol. 9(8), pp. 1614-1624, 2016.

[7] M. Malinowski, M. Jasinski, and M.P. Kazmierkowski, "Simple direct power control of three-phase PWM rectifier using space-vector modulation (DPC-SVM)," IEEE Trans. Ind. Electron., vol. 51(2), pp. 447-454, 2004.

[8] J. Hu, J. Zhu, and D.G. Dorrell, "In-depth study of direct power control strategies for power converters," IET Power Electron., vol. 7(7), pp. 1810-1820, 2014.

[9] A. M. Razali, M.A. Rahman, and Glyn George, "An analysis of direct power control for three phase AC-DC converter," Industry Applications Society Annual Meeting (IAS), pp. 1-7, 2012.

[10] Nor Azizah Mohd Yusoff, Azziddin Muhammad Razali, Kasrul Abdul Karim, Loong Jie Yan, "A direct power control of AC/DC converter," Journal of Engineering Sciences and Techonology, pp. 13-21, 2019.

[11] A. M. Razali, M.A. Rahman, "Performance analysis of three-phase PWM rectifier using direct power control," in International Electric Machines \& Drives Conference(IEMDC), pp. 1603-1608, 2011.

[12] Hu, J., Zhu, J., and Dorrell, D.G., "A comparative study of direct power control of AC/DC converters for renewable energy generation," IECON 2011 - 37th Annual Conference of the IEEE Industrial Electronics Society, pp. 3578-3583, 2011.

[13] Nian, H., Shen, Y., Yang, H., and Quan, Y., "Flexible grid connection technique of voltage-source inverter under unbalanced grid conditions based on direct power control," IEEE Transactions on Industry Applications, vol. 51(5), pp. 4041-4050, 2015.

[14] Suh Y., Lipo T.A., "Modeling and analysis of instantaneous active and reactive power for PWM AC/DC converter under generalized unbalanced network," IEEE Transactions on Power Delivery, vol. 21(3), pp. 1530-1540, 2006.

[15] Xiao, P., Corzine, K.A., and Venayagamoorthy, G.K., "Multiple reference frame-based control of three-phase PWM boost rectifiers under unbalanced and distorted input conditions," IEEE Transactions on Power Electronics, vol. 23(4), pp. 2006-2017.

[16] Muangruk, N., and Nungam, S., "Direct power control of three-phase voltage source converters using feedback linearization technique," Procedia Computer Science, 86(March), pp. 365-368. 2016.

[17] Nian H., at al., "Improved direct power control of a wind turbine driven doubly fed induction generator during transient grid voltage unbalance," IEEE Transactions on Energy Conversion, vol. 26(3), pp. 976-986, 2011.

[18] Prasad, P.B., "A multilevel inverter based dual voltage source inverter design for improving power quality of grid," International Journal of Electrical and Computer Engineering, vol. 8(2), pp. 121-137, 2016.

[19] Tapan, "A review on direct power control for applications to grid connected PWM converters engineering,"Technology \& Applied Science Research, vol. 5(4), pp. 841-849, 2015.

[20] Zhang, Y., and Qu, C., "Model predictive direct power control of PWM rectifiers under unbalanced network conditions," IEEE Transactions on Industrial Electronics, vol. 62(7), pp. 4011-4022, 2015.

[21] Imad Merzouk and Mohamed Lomane Bendaas, "Improved direct power control for 3-level AC/DC converter under unbalnced and/or distorted voltage source conditions," Turkish Journal of Electrical Engineering \& Computer Sciences, vol. 24, pp. 1847-1862, 2016.

[22] Merzouk I, Bendaas ML, Gaafazi A, and Rizaoui M., "Improved direct power control for three-level AC/DC converter under unbalanced voltage source conditions," $1^{\text {ST }}$ International Conference on Power Electronics and Their Application". Nov 2013.

[23] Nor Azizah Mohd Yusoff, Azziddin Muhammad Razali, Kasrul Abdul Karim, Tole Sutikno, and Auzani Jidin, "A concept of virtual-fluxdirect power control of AC-DC converter," International Journal of Power Electronics and Drive System (IJPEDS), vol. 8(4), pp.1176-1784, Dec 2017.

[24] Nor Azizah Mohd Yusoff, Azziddin Muhammad Razali, Kasrul Abdul Karim, Tole Sutikno, and Auzani Jidin "An analysis of virtual-fluxdirect power control of AC-DC converter," International Journal of Power Electronics and Drive System (IJPEDS), vol. 9(3), pp.947-956, Sep 2018. 